\title{
LESSONS LEARNED AND SCARS FORMED FROM CREATING MULTIPLE OPEN ENTRY CBE PROGRAMS AT THE COMMUNITY COLLEGE \\ Eric Heiser, PhD
}

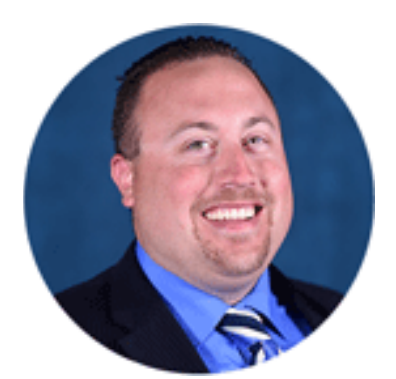

Eric Heiser, PhD. School of Applied Technology \& Technical Specialties, Salt Lake Community College, 4600 S Redwood Rd, Salt Lake City, UT 84123, United States; eric.heiser@slcc.edu

KEY WORDS: CBE, hybrid, non-term, administration, higher education, competencybased education

\section{INTRODUCTION}

In early 2014, Salt Lake Community College (SLCC) embarked on what has become a gigantic task, transitioning 20 clock-hour, seat-time based programs to Competency-Based Education (CBE). With the help of a $\$ 2.3$ million dollar Department of Labor Trade Adjustment Assistance Community College and Career Training (TAACCCT) grant, the project began in earnest in the summer of 2014 and continues today. This article will recap the highs, lows, and everything in between in an effort to help institutions who may be considering a move to CBE.

First, a couple of disclaimers. We have presented the SLCC model at numerous national and international conventions and always start each presentation with the disclaimer that we are not experts, nor is our way the only way to do CBE. In fact, if we've learned anything over the past three years it's that each school is going to have its own flavor of CBE. That is perfectly acceptable and frankly the only logical way to approach the move to $\mathrm{CBE}$. So long as the program is guarded by quality standards (more on that later) and measureable, meaningful assessment, institutions should do what works for them as opposed to trying to mirror what others have done. Each institution is unique and will have their own set of issues with which to consider. 
Second, we have (knowingly) made things harder on ourselves than they have to be. We operate our CBE programs on an open-entry format. Students can start most Monday's throughout the year. This, as you might imagine, is incredibly challenging when it comes to systems, faculty, and generally everything in higher education. While it certainly makes CBE more accessible to students, open-entry is not a requirement to run a CBE program. There are many programs throughout the country who operate on the standard term (semester or quarter) and have done so very successfully. Our model was one of necessity due to some specific state regulations and funding obligations.

\section{THE BEGINNING}

SLCC chose to start CBE in the School of Applied Technology (SAT). This school is tasked with providing open-entry, short-term, workforce training to the underserved, underemployed, and unemployed. The SAT was already operating on an open-term format and since it has a direct connection to workforce, it seemed like the logical choice to pilot the CBE project. The school has over 20 programs in areas from Electronics and Computer Networking to Commercial Truck Driving and Culinary Arts. It also has robust healthcare offerings for those looking to get into entry or mid-level positions. All of the programs within the SAT were non-credit, clock-hour programs. Our goal in the TAACCCT grant was to transform these programs into CBE while also creating pathways to Associates Degrees for those students who received training and wanted to further their education at some point down the line. While this seems like common sense, the noncredit/credit pathway was not something that had ever truly been flushed out. More than two years into the project, it was one of the best decisions we chose to make.

SLCC was one of the first two community colleges in the nation invited to join the newly formed Competency-Based Education Network (C-BEN) in early 2014. This group was put in motion with funding from Lumina Foundation in an effort to come to a common understanding of what quality CBE looks like and how to help schools who were either already offering some form of $\mathrm{CBE}$ or were close to launching. The original cohort consisted of 15 schools with just two community colleges (SLCC and the Kentucky Community and Technical College System). C-BEN has been a tremendous asset in getting quality standards published for greater consumption and continues to function in that role today. SLCC would not be where we are today without the tremendous help of this network.

\section{THE PROCESS (THE FIRST LESSON LEARNED)}

We started our CBE transformation process by pairing teams of faculty, instructional, and assessment designers. We thought that the roles were clearly defined and that each person had knowledge of what they needed to do in order to create a successful CBE 
course. This was our first mistake. It didn't take long for faculty to start feeling disenfranchised by what they felt was overreach by both the instructional and assessment designers. What one side felt was their job, the other side felt was overreach. The relationship between faculty and instructional design has always been one of cautious approach. Faculty don't like being told what to do. They are the subject matter experts, period. My days of teaching confirm this as well. I was always suspicious of what instructional designers were wanting to do and why they thought they knew better than me when it came to teaching my course. The fact is though, that instructional designers do play a key role in assuring quality CBE design and assessment. Not having specifically trained designers makes things much harder on the faculty as they get to play dual roles when the design team isn't involved. The key in this area is to ensure that all parties know who's driving the bus. I liken this process to having 15 people on a bus and each person having a steering wheel. Without a common goal or direction, the bus is paralyzed with each of the 15 going in their own direction. To solve this, we found it was best for Faculty to drive the bus. We did this for numerous reasons, but probably the biggest centered on the need for true faculty buy-in and support as the CBE pilot got off the ground. If you want to know the number one way to derail a fledgling program, try starting it without faculty support.

Nearly two and a half years in, we still have some issues but they are mainly personality related. We have developed internal rubrics that both sides had input on and it seems to be helping things flow a little more smoothly. Again, this is a relational dynamic that already tenuous at best and then throwing a brand new way of learning (CBE) into the mix makes it all the more stressful. We are using a hybrid-model rubric that brings together elements of design from the C-BEN Quality Standards Document (Competency-Based Education Network, 2018) as well as the Quality Matters guidelines (Quality Matters, 2014) for those courses that have an online component.

\section{SLOW AND STEADY (THE SECOND LESSON)}

At nearly every conference presentation we've given, we have preached the need for schools to approach CBE with a tortoise mindset as opposed to the hare. In other words, slow and steady wins the race. There are so many great things that CBE does for students and sometimes institutions can be prone to wanting to get there quickly. However, as we have found, trying to do too much can lead to burnout, or worse, losing key people from your team. When we initially wrote the TAACCCT Grant, our line of thinking was that it had to be something big in order to impress the Department of Labor enough to award over two-million dollars. We thought (wrongly) that we had a quasi-CBE set up and could transition our programs easier than many schools who may be starting from scratch. What we really had was the bare bones of an operation that still needed much work and 
refinement prior to launch. In fact, we are constantly refining our processes and procedures to align with what we have found to be new and better ways of developing courses and programs. That's not necessarily a bad thing, however, it's important to note that it still took valuable time away from our grant schedule. To date, we have 13 programs operating on the CBE format. We still have seven more programs to transition prior to the end of the grant in the fall of 2018. Knowing what we know now, we would have written for far fewer (think half) of the programs we initially wrote for and would have been able to spend more time in the early stages of development. Again, we don't have the luxury of hindsight and we are confident we will make the deadline in our grant timelines. But, we have learned a very valuable lesson in the process and its one that institutions who are either just starting or considering to start should heed, take your time.

\section{THE THREE S'S (LESSONS THREE, FOUR, AND FIVE)}

By far the biggest obstacles that we've faced, and frankly many of our peer institutions have as well, deals with what I like to call the three S's: Systems, Support, and Sustainability. I'll cover each of these in a separate portion of this article but they are important to keep in mind as an institution considers the move to CBE.

\subsection{Systems}

One of the biggest problems we, and others, have faced have to deal with the systems we currently use in Higher Education. The two major players in the systems category deal with an institution's Student Information System (SIS) and its Learning Management System (LMS). Between these two systems, there's a bevy of problems when it comes to transitioning courses and programs to CBE. Let's start with the SIS. First, the two biggest players in the market have been lukewarm, at best, when it comes to having their systems work in a non-term environment. In fact, one of the big SIS players just dropped out of the CBE LMS market altogether. This should be a bit of a cautionary tale for the users of this system. Due to this decision, some schools have now been left with nothing after choosing to go with this particular vendor. The news on SIS's isn't all bad though, institutions choosing to stay on a term-based schedule would have an easier time than what we have experienced. That said, the SIS is the data hub for an institution and your IT area will need to be comfortable with the tasks that will be coming with regard to CBE. For instance, data reporting will change with regard to students finishing one class in the middle of a semester and starting another. This is not a normal operation in our traditional academic calendar. These are issues we've had to work around internally and build our own systems within the SIS to accommodate. They take time and talent and can easily add months to the design process. 


\subsection{Support}

Support comes in many facets and functions but for the purposes of CBE, it needs to start at the top. Institutions considering a transition to CBE must carefully consider what they are willing spend and how much support will be needed to ensure the transition has a good shot at success. To that end, we've found that without Presidential and Executive Cabinet support, a transition to CBE wouldn't be possible. There are numerous reasons for this, but all center around the inevitable hard situations that will occur. When these hard situations occur and choices have to be made, others will look to the top to see just how much "support" is coming from that direction. Without a constant and consistent message of support from the top there will be people who won't be bought into the process who may see that as an opportunity to drag feet or hold processes up. Initiatives like CBE will take time and institutions need to consider the fact that there will be problems along the way. When the problems are expected and the philosophy is one of "how do we fix this" instead of "this will never work", the initiative is much more likely to be successful. We've been blessed with unwavering support from both our President and Provost as well as the entire Executive Cabinet. I firmly believe that without that support we would have stopped what we were doing long ago and simply continued using what we knew was a flawed model. While these discussions aren't always comfortable, they need to be had, and agreement must be reached at the highest levels (President, Board, etc.) prior to embarking on the journey. It will save a great amount of heartache and also serve to put those on notice who may not be entirely bought into the transition.

\subsection{Sustainability}

The last, appropriately, is sustainability. Simply put, how will you continue after the initial support is gone? If you're using a grant, what are the plans once the grant monies run out? The last $S$ could also be scalability. As I've noted earlier in this article, one of our greatest lessons learned stems from choosing far too many programs to pilot. Starting small is by far the most prudent and cost-effective way to determine if CBE is going to work with your institution. However, what happens when the pilot is over? Even more importantly, what happens when it works? How will your institution come to scale your CBE programs? While it may be easy to run things in a manual format in the beginning (p.s., we're still doing it!), it's not a sustainable way to continue as CBE grows within the institution. Especially if the plan is to run CBE on a non-term or hybrid term environment, it is vitally important for the institution to be thinking, at the very early stages of the project, about how scale will be achieved when success is reached. This is certainly not to say that you must figure everything out, however, it never hurts to be planning on a parallel path as the project gets up and running. Scale was one of the things we started talking about within a year of our first programs moving to CBE. We could see there was some success and we 
felt that it had merit and that others within the institution would be interested in taking their programs to $\mathrm{CBE}$. One of the biggest challenges to date has been the fact that the systems (the first $S$ ) haven't come to market as quickly as expected. While that is more than a minor challenge, it has not kept us from planning as to how we'll roll out CBE to the larger college. Rather, the plan has shifted from what we don't have to what we do have. From that, we've developed a type of both best case and worst case scenarios. The bestcase is that the vendors come through and deliver what they are promising. If that happens, we'll be in a much better spot than we are now because we're planning for the worst-case scenario. The worst-case scenario is that we end up developing patchwork solutions in-house and build the car as we drive it. That won't be altogether different than what we've done thus far but that is far from the optimal solution. Most likely, we'll end up somewhere in the middle.

\section{CONCLUSION}

While the list in this article is not meant to be comprehensive and in no way does it list all of the things we've run into as we've started our CBE journey, I feel these are the most important at this point in the process. Most importantly, these seem to be the same issues that have tripped up other institutions as I've visited with colleagues in this space. It seems we can all agree that this list is a good start for institutions to consider as they begin to deliberate what CBE might look like at their school.

While this list may seem overly negative and rife with trouble, the one message I hope you take from this article is this: CBE is worth the trials and tribulations. We are nearly three years into our project and we are just barely starting to see the fruits of our labor. To date, we've run nearly 400 students through our CBE programs and we are starting to see some very promising results. In some cases, we've seen completion rates more than double. I would caution that these are still not statistically significant results as our numbers are still too small to bear that out; however, the early results are showing a lot of promise. In addition to the rise in completions, we're also seeing our students finish at or just prior to the average time to completion. This, in and of itself, is incredibly promising for our programs. Prior to making the move to CBE we struggled to keep students on track. Some students were staying in one-year programs for four or five years! Even if the completion rates come down, having students complete on time would be more than enough reason for us to continue down the CBE road.

We truly believe that CBE is worth it. We believe that the flexibility created with our openenrollment and open classroom model is something that fits the lives of our students and helps them successfully complete and move into the workforce. No matter which way you decide to implement a program, term or non-term, open or traditional enrollment, I would 
strongly encourage you to give it a shot. Anything we can do to enhance the chances of our students passing and completing our courses and getting them placed into higher paying jobs is certainly worth the struggles mentioned in this article.

\section{REFERENCES}

Competency-Based Education Network (2018). Competency-Based Education Network (C-BEN) Design Planner. Retrieved October 1, 2017 from https://www.cbedesignplanner.org/

Quality Matters (2014). Higher Ed Course Design Rubric Standards, Fifth Edition. Retrieved October 1, 2017 from https://www.qualitymatters.org/qa-resources/rubricstandards/higher-ed-rubric 